\title{
An Investigation into the General Applicability of Quantification of Trace Ti in Quartz by Cathodoluminescence
}

\author{
$\underline{\text { C.M. MacRae }}^{*}$, N.C. Wilson ${ }^{*}$, W.P. Leeman ${ }^{* *}$, E.P. Vicenzi ${ }^{* * *}$, A. Torpy*, O. Vasyukova ${ }^{* * * *}$, K. \\ Goemann $^{* * * *}$, and P. Hasalova \\ * $\quad$ Microbeam Laboratory, CSIRO Process Science and Engineering, Clayton South, VIC, 3169 \\ ** National Science Foundation, Earth Sciences Division, Arlington, VA 22230 \\ *** Department of Mineral Sciences, Smithsonian Institution, Washington, DC 20560 \\ **** $\quad$ ARC Centre of Excellence in Ore Deposits, Uni. Tasmania, Hobart, TAS, 7001 \\ ****** School of Geosciences, Monash University, Clayton Campus, VIC, 3800
}

Recent experimental calibration of Ti concentration in quartz ${ }^{1,2}$ provides the basis for a quantitative examination of crystal growth in both hydrothermal and geothermal forms. Quartz contains trace element fluctuations, at the micron length scale, which are records of the complex interaction between crystals and their host magmas or fluids. Cathodoluminescence (CL) is an excellent probe for examining the growth dynamics and trace element distributions, as it provides the spatial data across grains in relatively short times. By combining spectral CL mapping ${ }^{3}$, deconvolution and elemental analysis to provide a calibration curve, it is possible to covert a CL intensity map into a trace speciation map for Ti. The trace level Ti can then be recalculated into a temperature scale, providing the appropriate thermal calibrations have been made and that the pressure of formation is taken into account ${ }^{4}$.

Cathodoluminescence spectral maps were collected on a range of quartz grains from three different deposits using a JEOL $8500 \mathrm{~F}$ equipped with an integrated grating spectrometer $(250-980 \mathrm{~nm})$. The maps were collected at analytical conditions of $20 \mathrm{kV}, 40 \mathrm{nA}, 40 \mathrm{~ms}$ dwell and steps of 2 micron per pixel, using a $300 \mu \mathrm{m}$ fibre. Under these conditions the CL emission spectra behaved with a linear response to beam current and no beam damage was observable on the mapped grains, indicating that we are below the damage threshold for quartz.

A quartz grain from a biotitic bearing granite porphyry from Climax porphyry molybdenum mine, central Colorado, USA, has been studied, and Figure 1 shows an example of a spectra collected at a pixel. It has been fitted using three Gaussians (1.92eV Intrinsic, 2.07eV Self trapped exciton (STE), and $2.72 \mathrm{eV} \mathrm{Ti}^{4+}$ ) using a least squares fitting approach. The fitted map of the $2.72 \mathrm{eV}$ peak is shown in Figure 2. A number of growth zones within the grain are visible exhibiting a significant intensity range in the $2.72 \mathrm{eV}$ peak. To calibrate the CL emission peak at $2.72 \mathrm{eV}$ against Ti a number of point analyses, shown in Figure 2, were performed using the electron microprobe and the resulting calibration curve is shown in Figure 3. Analysis conditions were 20kV, 150nA, 10um spot, two PET spectrometers analysed $\mathrm{Ti} \mathrm{K} \alpha$ resulting in an overall 3-sigma detection limit of $10 \mathrm{ppm}$. The fitted calibration line to the data shows the highly linear response of Ti concentration to $2.72 \mathrm{eV}$ peak with a goodness of fit $\left(\mathrm{R}^{2}\right)$ being 0.954 . Applying this calibration to a second mapped quartz grain, Figure 4, results in a Ti map with detections limits per pixel of only a few ppm.

The $2.72 \mathrm{eV} \mathrm{CL}$ peak was found to correlate with a range of $\mathrm{Ti}$ concentrations across the three deposits studied. The Ti concentrations were measured both electron microprobe, as above, and by LA ICP-MS giving support to the general applicability of this technique. 


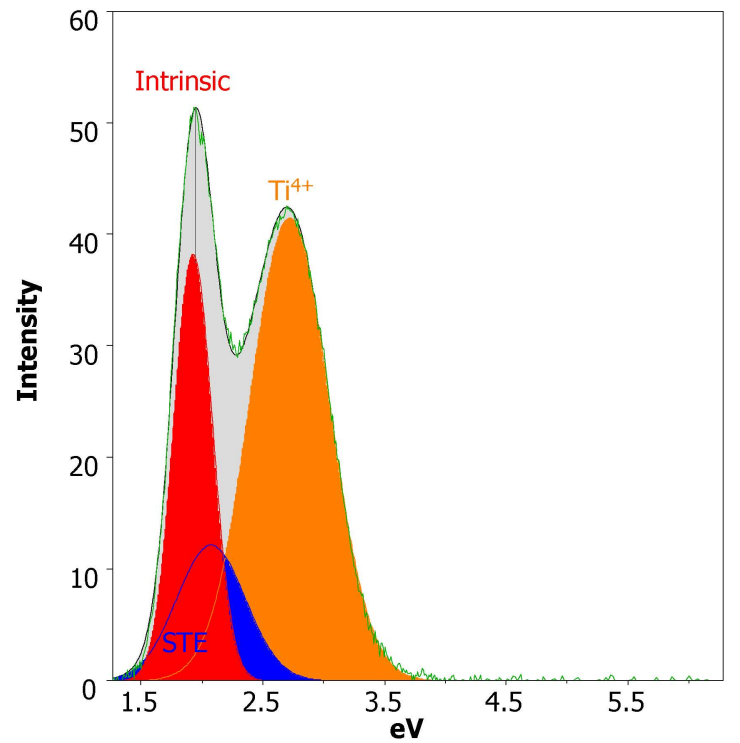

Figure 1. An average cathodoluminescent spectra collected from the quartz grain in Figure 2. Three Gaussians, attributed to Intrinsic, STE and $\mathrm{Ti}^{4+}$ centre, are used to fit the spectra each pixel of the map.

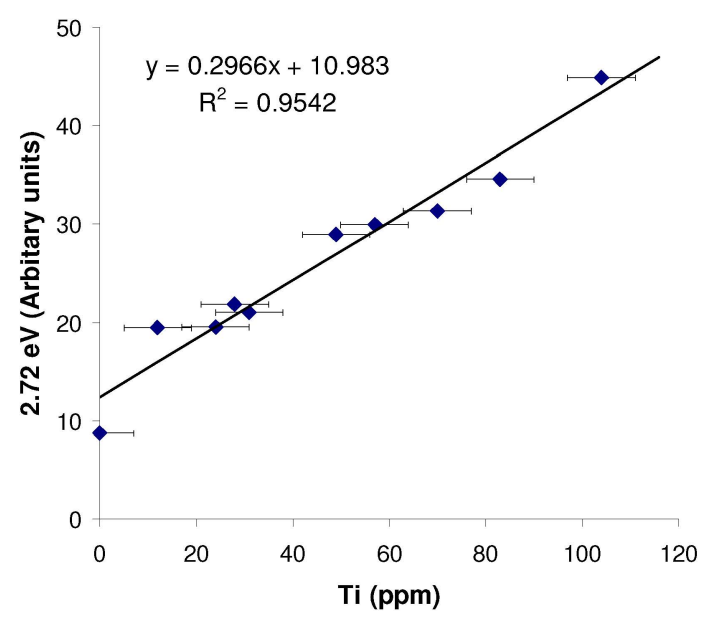

Figure 3. Elemental $\mathrm{Ti}$ versus the $2.72 \mathrm{eV}$ peak attributed to $\mathrm{Ti}^{4+}$. The lineal response is used to calibrate the fitted quartz map. The $\mathrm{R}^{2}$ value for the fitted response is 0.954 showing excellent agreement between point analysis and the mapped CL.
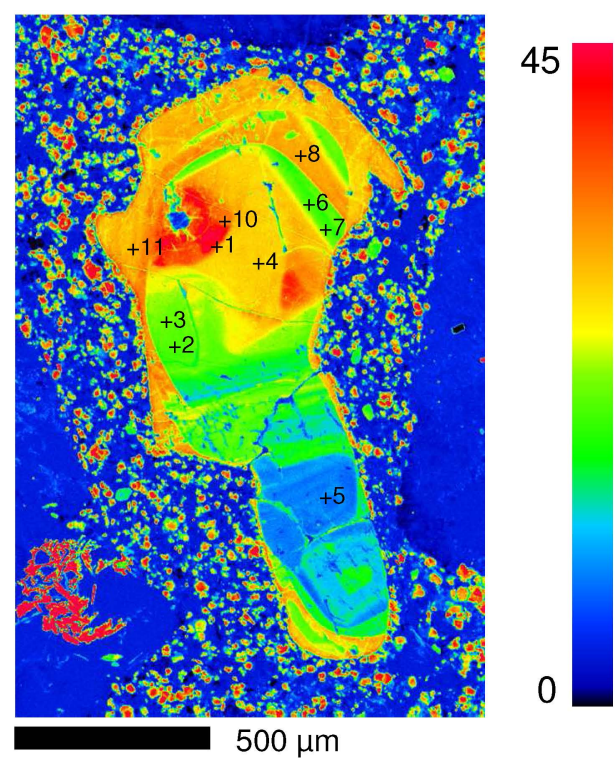

Figure 2. Fitted CL $2.72 \mathrm{eV}$ intensity map of a quartz grain showing quantitative analysis points which are used to calibrate the CL response with Ti concentration.

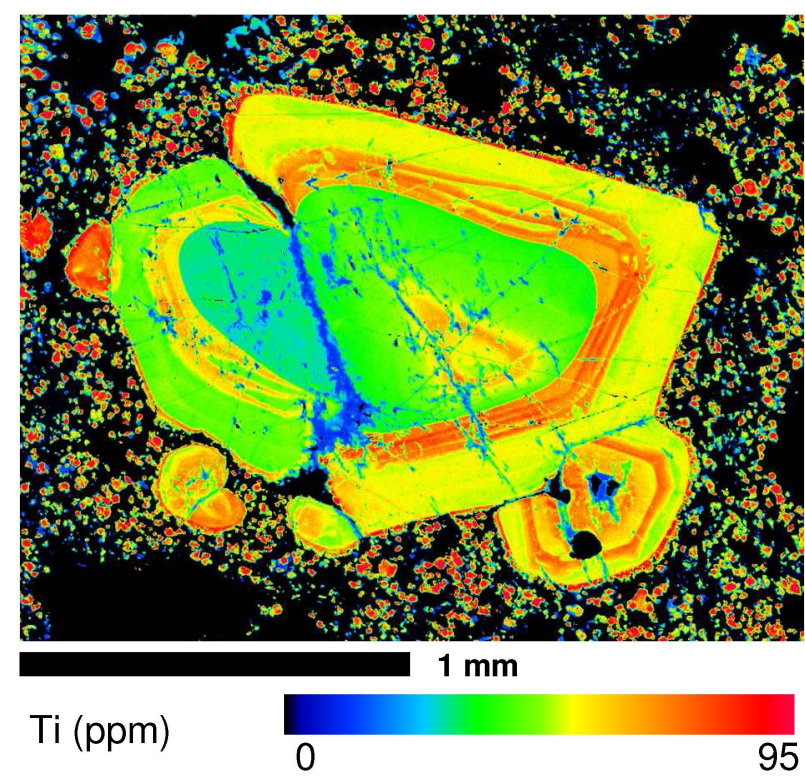

Figure 4. Second quartz grain which has been fitted and calibrated showing the $\mathrm{Ti}^{4+}$ expressed in part per million. Grain shows healed crack and a number of growth zones.

\section{References:}

[1] H D.A. Wark and E.B. Watson. Contrib. Mineral. Petrol. 152 (2006) 743.

[2] F.S. Spear and D.A. Wark. Metamorphic Geol., 27 (2009) 187.

[3] C.M. MacRae et al., Proc. ACMM-20 \&IUMAS-IV. Perth, Australia (2008).

[4] W.P. Leeman et al. Microsc. Microanal. 14, Suppl. 2, (2008) 38. 